
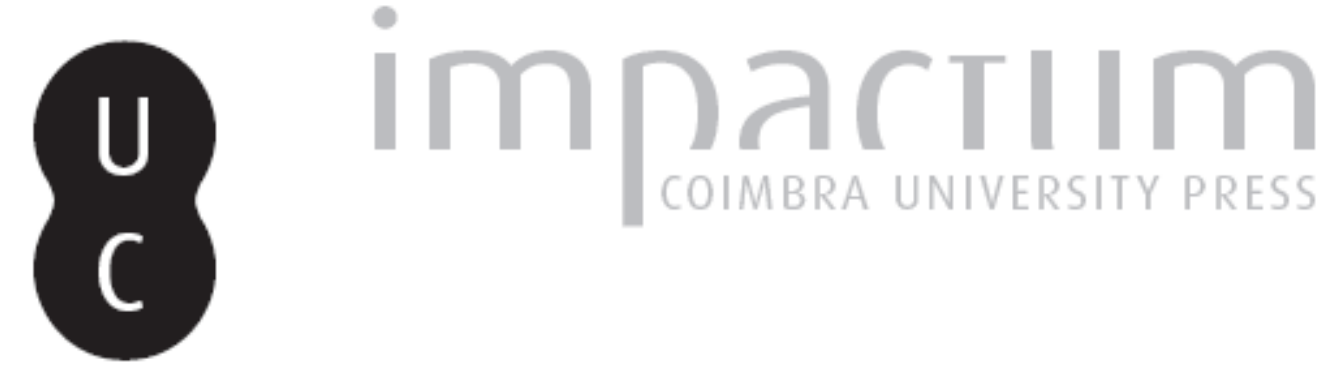

[Recensão a] Incêndios florestais em Portugal continental fora do "período crítico",
estudados numa tese que fornece importantes contributos para o seu conhecimento

Autor(es): Lourenço, Luciano

Publicado por: Imprensa da Universidade de Coimbra

URL

persistente:

URl:http://hdl.handle.net/10316.2/43280

DOI:

DOI:https://doi.org/10.14195/1647-7723_25-1_13

Accessed : $\quad$ 26-Apr-2023 12:36:11

A navegação consulta e descarregamento dos títulos inseridos nas Bibliotecas Digitais UC Digitalis, UC Pombalina e UC Impactum, pressupõem a aceitação plena e sem reservas dos Termos e Condições de Uso destas Bibliotecas Digitais, disponíveis em https://digitalis.uc.pt/pt-pt/termos.

Conforme exposto nos referidos Termos e Condições de Uso, o descarregamento de títulos de acesso restrito requer uma licença válida de autorização devendo o utilizador aceder ao(s) documento(s) a partir de um endereço de IP da instituição detentora da supramencionada licença.

Ao utilizador é apenas permitido o descarregamento para uso pessoal, pelo que o emprego do(s) título(s) descarregado(s) para outro fim, designadamente comercial, carece de autorização do respetivo autor ou editor da obra.

Na medida em que todas as obras da UC Digitalis se encontram protegidas pelo Código do Direito de Autor e Direitos Conexos e demais legislação aplicável, toda a cópia, parcial ou total, deste documento, nos casos em que é legalmente admitida, deverá conter ou fazer-se acompanhar por este aviso.

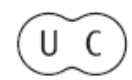


territorium/25w|.

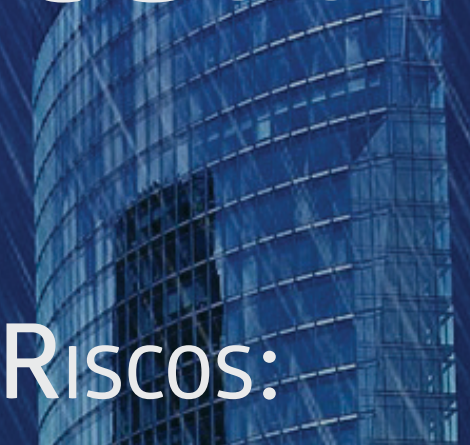

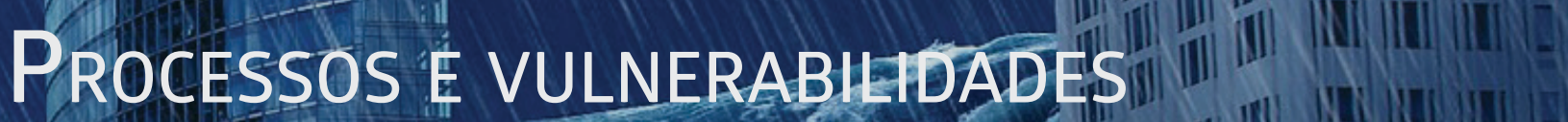

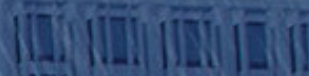
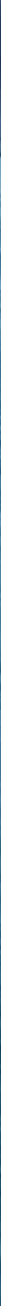

Imprensa da Universidade de Coimbra

Associação Portuguesa de Riscos, Prevenção e Segurança

2018 


\section{INCÊNDIOS FLORESTAIS EM PORTUGAL CONTINENTAL FORA DO “PERÍODO CRÍTICO”, ESTUDADOS NUMA TESE QUE FORNECE IMPORTANTES CONTRIBUTOS PARA O SEU CONHECIMENTO}

Luciano Lourenço

Departamento Geografia e Turismo, CEGOT e RISCOS, Universidade de Coimbra (Portugal)

luciano@uc.pt

Os muitos incêndios florestais e alguns deles de grande dimensão que, no início de outubro de 2017, lavraram sobretudo no Norte e Centro de Portugal, trouxeram-me à memória outros grandes incêndios que, por uma ou outra circunstância acabei por nela reter, designadamente o de Águeda, em 1986 (L. Lourenço, 1988) e, mais recentemente, o de Castanheira de Pera, em 2011 (L. Lourenço e J. Fernandes, 2012) e, no ano seguinte, os de Penela. Ora, por todos eles terem atingido dimensões significativas e se terem desenvolvido fora do chamado "período crítico" (correspondente à anteriormente designada "época de fogos"), mereceram ser tratados numa tese de mestrado, que deu azo a esta recensão, a qual pretende contribuir para a divulgação deste importante trabalho sobre um tema pouco conhecido.

Com efeito, com maior frequência do que habitualmente se considera, fora do chamado "período crítico", ocorrem incêndios florestais que, quando as condições meteorológicas são favoráveis ao seu desenvolvimento, podem alcançar elevada intensidade e perdurar durante vários dias, reduzindo a cinzas extensas áreas de floresta, como sucedeu com vários incêndios registados entre 6 e 10 de outubro e, sobretudo, depois, com os que alastraram no fatídico dia 15 de outubro, cuja área total de momento ainda não foi apurada, mas que deverá ter sido superior a 100000 ha.

Por essa razão e com o objetivo de perceber a dimensão e as caraterísticas deste fenómeno, a Licenciada Sofia Fernandes propôs-se estudá-lo como tema da sua dissertação de mestrado (S. Fernandes, 2015), um estudo (fig. 1) que, entre outros objetivos e no dizer da autora, pretendeu "contribuir para um conhecimento mais amplo das condições meteorológicas e das causas humanas, que estão na origem dos incêndios florestais que deflagram fora da época da sua maior incidência, ou seja, num período em que o Dispositivo Especial de Combate a Incêndios Florestais (DECIF) se encontra alocado às fases ALFA, BRAVO, DELTA e ECHO, caracterizadas por um menor número de meios de combate (terrestres e aéreos) e menos recursos humanos disponíveis, ao contrário do que sucede na época de maior incidência, na qual vigora a fase CHARLIE, onde há um reforço geral do dispositivo" (o. c., p. 21), fase esta (CHARLIE) que coincide com o chamado "período crítico".
A autora desenvolveu o seu raciocínio partindo da caraterização dos "incêndios florestais em Portugal Continental", que serve de título e trata no primeiro capítulo da tese, o qual funciona como nota introdutória aos restantes, na medida em que aborda, de forma sucinta, a temática dos incêndios florestais em Portugal Continental, focando o seu enquadramento no contexto europeu, na sua evolução temporal e distribuição espacial (por distritos), bem como nas respetivas tendências, distinguindo os incêndios florestais que ocorrem dentro do "período crítico" daqueles que se registam fora dele.

Depois, no segundo capítulo, denominado “incêndios florestais registados em Portugal Continental fora do 'período crítico', entre 1981 e 2012”, inicia o tratamento da temática em análise, apresentando um estudo detalhado sobre as ocorrências de incêndios florestais fora do "período crítico", que distribuiu em função da

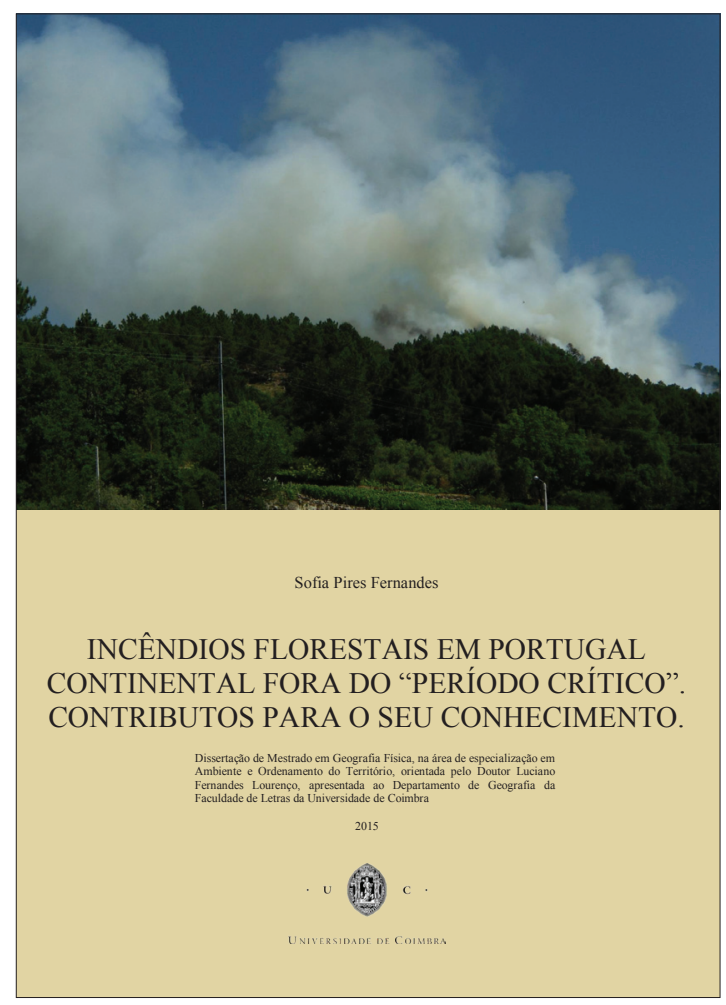

Fig. 1 - Frontispício da dissertação de mestrado de Sofia Fernandes.

Fig. 1 - Frontispiece of the Sofia Fernandes Master's Dissertation. 
sua tipologia, fogachos e incêndios florestais, bem como da anterior ocupação das áreas ardidas, povoamentos florestais e matos. Mostrou, ainda, a diferente incidência regional, por distritos, das ocorrências registadas fora da "época crítica”, o que possibilita conhecer a distribuição espacial do fenómeno dos incêndios florestais em Portugal durante a maior parte do ano, ou seja, fora da época estival.

O terceiro capítulo é dedicado aos "grandes incêndios florestais ocorridos em Portugal Continental fora do 'período crítico', entre 1981 e 2012" e nele analisa não só a ocorrência de grandes incêndios florestais ( $\geq 100$ ha) fora do "período crítico", mas também a sua distribuição espacial, a nível de distrito. A autora considera ainda as razões que, nos anos de 2005, 2011 e 2012, contribuíram para uma elevada ocorrência de incêndios nesses anos, precisamente fora do chamado "período crítico".

No quarto capítulo, intitulado "causas dos incêndios florestais que, fora do 'período crítico', eclodiram entre 1995 e 2012", a autora estudou, de forma suficientemente detalhada, as diversas fontes de ignição de incêndios florestais registadas fora do "período crítico", de acordo com as causas apuradas pelas entidades responsáveis, no local da ocorrência, referentes quer ao número de ocorrências, quer às áreas ardidas, e mostrou, ainda, a respetiva repartição espacial. Concluiu que as causas humanas são as principais responsáveis pela eclosão destes incêndios florestais e ilustrou a diferente incidência regional de cada uma das principais causas.

O quinto e último capítulo versa sobre "condições meteorológicas e ocorrências de incêndios florestais fora do 'período crítico': análise sinótica e índice de risco de incêndio florestal". Nele é tratada a influência que determinadas condições meteorológicas, associadas a diferentes situações sinóticas, mesmo quando observadas fora da "época crítica" de incêndios, podem ter na ignição e progressão de incêndios florestais.

Deste modo, no quinto capítulo, foi feita uma abordagem à circulação atmosférica à superfície (n. m. m.) e em altitude (500 hPa), registada nos 380 dias correspondentes aos das semanas mais críticas e que, posteriormente, relacionou com o número de ocorrências e com as áreas ardidas nesses dias. Além da componente sinótica, fez também uma comparação de elementos meteorológicos (precipitação, temperatura e humidade relativa do ar) registados em seis estações dispersas de Norte a Sul do país, com a ocorrência dos incêndios florestais, para verificar a relação existente entre essas condições meteorológicas, vertidas no índice Meteorológico de Risco de Incêndio Florestal, e a ocorrência de incêndios florestais.

Feita a apresentação genérica dos principais assuntos abordados, não podemos deixar de salientar a importância da dimensão que alguns destes incêndios alcançaram, dos quais, os quatro maiores, mereceram referência no Quadro VII, da p. 76, correspondendo a incêndios que se desenvolveram nos municípios de:

1. Águeda - o incêndio ocorreu entre 13 e 15 de junho de 1986, tendo consumido 4499 ha. Este incêndio não só foi o maior do período analisado, mas também foi o mais mortífero, uma vez que ceifou a vida a 13 bombeiros e a 3 civis.

Por casualidade, no ano de 2017, Águeda voltou a registar outro grande incêndio fora do período crítico, no dia 28 de abril, embora de dimensão bem inferior, mas que, ainda assim, queimou 282 ha (ICNF, 2017).

2. Mação - o incêndio ocorreu entre 26 e 30 de junho de 1991, tendo queimado 4017 ha, cifrando-se por isso como o segundo maior incêndio do período considerado. Este município voltou a ser palco de grandes incêndios no verão de 2017, designadamente em 1 de julho, 16 de agosto e 23 de setembro, incêndios que somaram umaárea queimada de 7795 ha ICNF, 2017);

3. Vila Velha do Ródão - neste caso o incêndio lavrou de 10 a 12 de junho de 1999 e reduziu a cinzas 3150 ha. Trata-se de outro município que, em 2017, voltou a sofrer com os incêndios florestais, sobretudo nas imediações das conhecidas Portas do Ródão, um monumento natural de rara beleza, que the é conferida pela dureza dos quartzitos que se elevam em crista, tanto para Norte como para Sul do rio Tejo, e cuja vegetação foi incinerada na sua quase totalidade, ao longo da crista quartzítica.

4. Tavira - registou um incêndio entre 30 de junho e 2 de julho de 2004, que queimou 3242 ha. Aliás, este foi o segundo grande incêndio desse ano no concelho de Tavira, uma vez que o primeiro tinha ocorrido três dias antes, a 27 de junho, tendo queimado 557 ha (DGRF, 2004).

De facto, este ano de 2004 começou muito mal no distrito de Faroe, porque se seguiu ao anterior de 2003 , o mais traumático em termos de incêndios florestais anteriores a 2017, começou por ser muito preocupante. Com efeito, a 25 de julho, registaram-se quatro grandes incêndios, nos municípios de Monchique, Alcoutim, Castro Marim e Faro que, respetivamente, queimaram 1 079, 2 654, 4087 e 187 ha (DGRF, 2014). Todavia, como se isso já não fosse suficiente, o maior incêndio desse ano ainda estava para vir.

Esse incêndio teve início no dia seguinte, 26 de julho, e apesar de ter começado no distrito de Beja, acabou por avançar para sul e terminar no de Faro, tendo reduzido a cinzas 25717 ha (DGRF, 2004).

Deste modo, nesse ano e só no distrito de Faro, terão ardido mais de 30000 ha até final de julho, o que deixava pressupor um novo ano traumático, mas, 
felizmente, o mês de agosto foi fresco, o que permitiu uma certa acalmia, depois de um início de “época” algo atribulado, sobretudo na região algarvia.

Em contrapartida, ao contrário do sucedido nos municípios anteriores, o ano de 2017 não registou nenhum grande incêndio no distrito de Faro.

Além destes quatro, a autora menciona outros grandes incêndios e também não resistimos a fazer uma pequena referência a alguns deles. 0 primeiro teve início a 14 de abril de 1995, no concelho de Albergaria-a-Velha e rapidamente evoluiu para um violento incêndio que foi responsável por devastar 2104 ha de área florestal, sendo visto como o segundo mais crítico do distrito de Aveiro, registado fora do "período crítico", entre 1981 e 2012, já que o primeiro tinha sido o supramencionado de Águeda (S. Fernandes, 2015, p. 76).

A autora refere este incêndio com o objetivo de comparar a semelhança das condições meteorológicas em que ele se desenvolveu, com aquelas em que progrediu o incêndio da Águeda, ou seja, ambas caracterizadas por baixos valores da humidade relativa do ar, a rondar 40\%, ausência de precipitação, temperatura máxima do ar acima de $20^{\circ} \mathrm{C}$ e vento moderado, por vezes forte, do quadrante Nordeste.

Cabe ainda fazer menção a duas outras situações, por serem mais recentes, pois dizem respeito aos dois últimos anos do período estudado e porque a primeira delas se desenvolve depois do "período crítico", enquanto que a outra se desenvolve antes dele e corresponde a dois incêndios, geograficamente próximos, mas que sendo posteriores àquele, se desenvolvem antes do início do novo "período crítico", ou seja, o primeiro diz respeito ao ano de 2011, enquanto que os segundos se registaram em 2012.

Assim, no final do ano de 2011, mais precisamente a 5 de outubro, teve início no concelho de Castanheira de Pera, distrito de Leiria, um incêndio florestal que rapidamente assumiu grandes proporções e alastrou ao concelho de Pedrógão Grande, tendo queimado 501 ha de floresta e mato e ameaçado várias povoações ao longo do seu percurso.

Apesar da sua importância e de ele se ter desenvolvido fora do "período crítico", tal como sucedeu com o que em 2017 teve início no vizinho concelho de Pedrógão Grande, a 17 de junho, por conseguinte, também fora do "período crítico", as respetivas consequências não são comparáveis, quer em termos de área, com este a deixar um rasto de destruição incomparavelmente maior, com a redução a cinzas de 27363 ha de espaços florestais e, sobretudo, em termos de vítimas, já que este ceifou a vida a 64 pessoas, tendo-lhes causado a morte, razão pela qual o ano de 2017 saltou para o topo das estatísticas, passando a assumir o primeiro lugar em número de mortos provocado por incêndios florestais e, muito provavelmente após o apuramento da área queimada em outubro, o primeiro lugar no ranking da quantidade de área ardida.

Por fim, os últimos dois grandes incêndios estudados fora do "período crítico" dizem respeito ao concelho de Penela, do distrito de Coimbra, tendo deflagrado, respetivamente, a 28 de março de 2012, na freguesia de Espinhal, onde arderam 972 ha, e a 29 de março de 2012, na freguesia de São Miguel, onde se queimaram 910 ha (ICNF, 2012).

A propósito destes e de outros incêndios, a autora desenvolve um conjunto de aspetos relacionados com as causas e com as condições meteorológicas que se revelam fundamentais para compreender o desenvolvimento dos incêndios fora do "período crítico" e que não cabe aqui desenvolver, mas que the permitiram retirar diversas conclusões, de entre as quais destacamos as seguintes:

1. A maioria das ocorrências registadas fora do "período crítico" corresponderam a fogachos ( $\leq 1 \mathrm{ha})$;

2. A maior área ardida correspondeu a incêndios florestais ( $\geq 1$ ha), apesar do maior número de fogachos, uma vez que os incêndios de grande dimensão são preponderantes na atribuição deste valor;

3. Uma parte substancial dos grandes incêndios florestais que ocorreram fora do "período crítico" consumiram áreas situadas entre 100 e 500 ha e apenas uma pequena parte alcançou área superior a 1000 ha, conclusão que foi contrariada com os incêndios de outubro de 2017;

4. A secura invernal, sobretudo quando se prolonga por vários meses, é propícia ao desenvolvimento de grandes incêndios florestais no início do ano, como sucedeu em 2005 e 2012;

Por sua vez, no que às causas diz respeito, a autora concluiu que:

1. Existem discrepâncias regionais na investigação das causas, bem notórias entre regiões que registam mais incêndios florestais e cuja investigação tende a ser menor, em contraponto com aquelas que, por registarem uma menor densidade de ocorrências por $100 \mathrm{~km}^{2}$, a investigação foi percentualmente maior;

2. A maioria dos incêndios florestais não foram investigados e quando o foram, na maior parte deles não houve apuramento da causa;

3. As ignições investigadas e cuja causa foi apurada, tiveram origem em ação humana, negligente ou intencional, em $55 \%$ dos casos, e em fenómenos naturais, em apenas $0,4 \%$ das situações. Os $44,6 \%$ restantes corresponderam a causas indeterminadas, uma vez que não foi possível identificar a respetiva origem; 
4. O uso negligente do fogo, em atividades ligadas a queimadas, para efeitos de renovação de pastagens ou a queima de sobrantes, tem sido a causa que mais incêndios florestais tem originado fora do "período crítico" e com especial incidência nos distritos do Interior Norte e do Centro Norte.

5. As motivações intencionais, assentes em atos imputáveis e de vandalismo do património florestal, fizeram-se sentir sobretudo nos distritos do Norte e Centro Litoral.

Por fim, no que às condições meteorológicas diz respeito:

1. A situação sinótica que correspondeu a mais de $60 \%$ dos incêndios florestais registados, esteve associada a uma circulação de trajeto continental, por isso, com ventos provenientes do quadrante Este (NE/E/SE).

2. Por sua vez, em altitude, a circulação meridiana foi a mais frequente, tendo grande parte dos incêndios florestais deflagrado sob condições de bloqueio anticiclónico ou, então, sob dorsais de correntes ondulatórias.

Como nota final diremos que se trata de um trabalho relevante sobre um tema pouco conhecido e muito atual, em matéria de incêndios florestais, como os incêndios de junho e de outubro de 2017 bem demonstraram. Por outro lado, não se limita à análise dos factos, uma vez que propõe soluções cuja implementação ajudaria a mitigar as consequências das manifestações deste tipo de risco, razões pelas quais bem merece uma leitura.

\section{Referências bibliográficas}

DGRF - DIRECÇÃO-GERAL DOS RECURSOS FLORESTAIS (2004). Incêndios florestais - 2004. Relatório Provisório (01 de janeiro a 10 de outubro de 2004). Divisão de Defesa da Floresta contra Incêndios, Lisboa, 12 p. http://www.icnf.pt/portal/florestas/dfci/relat/rel-if
ICNF - INSTITUTO DA CONSERVAÇÃO DA NATUREZA E DAS FLORESTAS (2012). Relatório anual de áreas ardidas e incêndios florestais em Portugal Continental - 2012. Departamento de Gestão de Áreas Públicas e de Proteção Florestal, Lisboa, 52 p.

http://www.icnf.pt/portal/florestas/dfci/relat/rel-if

ICNF - INSTITUTO DA CONSERVAÇÃO DA NATUREZA E DAS FLORESTAS (2017). 8. ${ }^{\circ}$ relatório provisório de incêndios florestais - 01 de janeiro a 30 de setembro de 2017. Departamento de Gestão de Áreas Públicas e de Proteção Florestal, Lisboa, 16 p.

http://www.icnf.pt/portal/florestas/dfci/relat/rel-if

Fernandes, Sofia (2015). Incêndios florestais em Portugal Continental fora do "período crítico". Contributos para o seu conhecimento. Dissertação de Mestrado em Geografia Física, na área de especialização em Ambiente e Ordenamento do Território, apresentada ao Departamento de Geografia da Faculdade de Letras da Universidade de Coimbra. Coimbra, 234 p. https://estudogeral.sib.uc.pt/bitstream/10316/28373/1/ Sofia Fernandes_Incêndios Florestais em Portugal Continental fora do período crítico.pdf

Lourenço, Luciano (1988). Tipos de tempo correspondentes aos grandes incêndios florestais ocorridos em 1986 no Centro de Portugal. Finisterra, Lisboa, XXIII, 46, p. 251-270.

http://revistas.rcaap.pt/finisterra/article / view/1975

Lourenço, Luciano; Fernandes, José (2012). Serra da Lousã: Mudanças na paisagem em consequência de incêndios florestais (Livro-guia da Viagem B). VII Colóquio de Geografia de Coimbra, Coimbra, 11 de fevereiro, 58 p.;

http://www.uc.pt/fluc/nicif/Publicacoes/Estudos_ de_Colaboradores/PDF/Livros_e_Guias/2012_Serra_ da_Lousa_0060.pdf 